\title{
TEARS OF TIME: A LEFEBVRIAN RHYTHMANALYSIS APPROACH TO EXPLORE THE MOBILITY EXPERIENCES OF YOUNG EASTERN EUROPEANS IN SPAIN
}

\author{
Silvia Marcu \\ Instituto de Economía, Geografía y Demografía \\ Consejo Superior de Investigaciones Científicas \\ Silvia.marcu@cchs.csic.es
}

This article explores the rhythm of temporary mobility experiences of young Eastern Europeans (EEs) in Spain, after the European Union (EU) enlargement towards the East. Following Lefebvre's rhythmanalysis approach, and drawing on 60 in-depth qualitative interviews, this article investigates how rhythms are linked to youth mobility and how different interplays of rhythms are connected and disconnected in multiple ways (Edensor and Holloway 2008). I argue that both the EU socio-economic context and the personal and professional life-course circumstances of young EEs who practice mobility create different, uneven rhythms of mobility that influence their everyday lives and their perceptions of mobility. This paper highlights the issue of rhythmic change in temporary mobility, uncovering 'arrhythmic' mobility -reflected in the loss and insecurity in the lives of those who practice it- 'polyrhythmic' mobility -practiced by people looking to study and/or work and expressed through uncertainty on the one hand and the possibility of establishing a certain rhythm in their lives on the other- and 'eurhythmic' mobility -used by those with a stable professional status in one of the EU countries, in this case, Spain. The conclusions provide a better understanding of Lefebvre's thinking, offering insights for wider applications. They show the need to integrate rhythmic change into the analysis of mobility, considering that the free movement of EU citizens across the open borders favours the fluid life-course that affects the experiences of the youth.

Key Words: rhythmanalysis, Lefebvre, mobility, precarity, migration, Eastern Europe.

\section{Introduction}

The 'mobility turn' has spawned a wave of thought-provoking research projects which have placed life-course and temporal mobility at the heart of geographical, social, corporeal and material experiences (Urry 2007; Hannam et al. 2006; Bissell 2009). In 
this context, rhythm becomes an important component of mobility (Edensor 2010a, b; Cresswell 2010; Mels 2004), is part of any social order, and is implicated in the production and contestation of social order.

Research concerning time-rhythm added various and rich explanations to the body of work on time and temporalities. Heidegger (1996) placed at the core of the analysis the concept of being-in-the-world to highlight the importance of time -as unity of the past, the present and the future- that in his view is both objective and subjective. Lefebvre is taking Heidegger's ideas and subjecting them to a radical critique, notably his understandings of everyday life, space and time (Elden 2004, 8). In his last work (2004), Lefebvre ambitioned the 'Rhythmanalysis project' as a method for the study of spatio-temporal rhythms. Addressing the concern of plural, different and specific rhythms, he returned to Bergson’s thought about rhythm. As Bergson (1910) suggested, the permeability of duration and extension lies in the fact that duration has many but different rhythms; it is a synthesis of the temporal and the spatial.

While Deleuze (1994) noted that rhythm is a crucial operator that links time, space and ordering, for Lefebvre, rhythm is the result of time 'that interacts with a place and an expenditure of energy’ (Lefebvre 2004,15). Importantly, he perceives the body as a point of contact between biological and social rhythm. Lefebvre uses rhythm as a tool or a method, rather than an object of analysis. As I outline below, the analysis of rhythms can also be used as a tool to reveal how they might be applied to exploring the mobility experiences of people; how they shape human experience in time-space and pervade everyday life (May and Thrift 2001; Edensor and Holloway 2008).

This article expands on Lefebvre's ideas and makes a distinctive theoretical, conceptual and empirical contribution to understanding rhythm, linking temporality to the 
geography of human mobility. Using the rhythmanalysis approach as an original qualitative method, the paper highlights how young people's lives are experienced through objective and subjective time, both in terms of their own rhythms and the rhythms of society. Drawing on in-depth interviews and involving the respondents themselves in the analysis as participants who experience their mobility, the research explores an innovative way of thinking highlighting the analysis of rhythms in the context of the precarity and job insecurity experienced by young Eastern Europeans (EEs) in Spain, after the European Union (EU) enlargement towards the East. As such, the focus on experiences becomes central to this novel use of the rhythmanalysis method.

In aiming to contribute to the emerging critical question of rhythm, this study develops a conceptual framework placing at the core of the analysis the issue of rhythmic change, to highlight 'arrhythmic' mobility, reflected by precarity, disturbances and desynchronisation, 'polyrhythmic' mobility, situated between instability and flexibility, and 'eurhythmic' mobility, composed of diverse and equilibrate rhythms. These concepts provide a suggestive background for the analysis of rhythms and their interplay in temporary mobility experiences, understood as a set of practices -work, careers, feelings, language- acquired through the life-course by different actors, who move and adapt to different environments in the context of time-space convergence (Cwerner 2001,14; Murphy-Lejeune 2002, 4; Findlay et al. 2015).

I have considered useful to focus this research on young EEs because the current EU economic crisis, which mainly affects Spain, is increasingly reflected in the precarious employment faced by young immigrants from this region in Spain. This unstable situation has influenced their living conditions and forced them to intensify their 
temporary mobility in seeking professional opportunities. I argue that both the EU socio-economic context and the personal and professional circumstances of EE citizens -to find work, to study overseas, to enjoy a scholarship, to travel for vacation, to work in a company- produce different interplays of rhythms, which connect and disconnect in multiple ways creating a rhythmic change in their mobility that influences their everyday lives, their narratives and their perceptions of rhythm.

The article is organised as follows. First, I briefly connect the paper with the broader literature on temporary mobility across the life-course. I then outline the theoretical framework and trace the trends of EEs' mobility towards the EU and Spain. I later explain the methodology used and analyse the interviews with young EEs to emphasise their temporary mobility experiences of rhythmic change. Finally, I reflect on the significance of my research in terms of better understanding and advancing Lefebvre's ideas. I highlight the need to integrate rhythmic change into the analysis of mobility considering that the free movement of the EU citizens across the open borders favours the fluid life-course that affects the experiences of the youth.

\section{Temporary mobility across the life-course of the young}

A mobility perspective is key for analysing the experience of the young in terms of lifecourse, transnational connections, and time and temporariness. This article draws on the recent migration and mobility literature that raises important questions about time and temporariness examining how rhythms are linked to the life-course temporary mobility (Shubin 2015; Collins and Shubin 2015; Griffith et al. 2013; Ansell et al. 2011;Collins 2012a;Cwerner 2001; Bailey 2009). 
First, authors (Collins and Shubin 2015; Findlay et al. 2015; Hörschelmann 2011) place the life-course concept at the centre of the debate on mobility, highlighting 'how the linked lives of mobile people are situated in time-space, within the changing economic, social, and cultural structures of contemporary society' (Findlay et al. 2015, 390; Elder et al. 2004). In turn, Bailey (2009) examined how life-courses are built over time, with accumulations of experiences, resources, and vulnerabilities shaping subsequent lifechances. Although Edensor and Holloway (2008) analysed how different interplays of rhythms are connected and disconnected in multiple ways, the recent literature does not engage with rhythm linked to the life-course in the temporary mobility experiences of the young. This article adds to the analysis of life-course in mobility, by examining the way in which the concept of experiences may be better understood in relation to the interpretation of rhythm.

Second, conceptualising youth mobility, authors (Bailey et al. 2002; Collins 2012a,b) highlight that transnational connections are held to be important resources for young people in advancing their socio-economic positions through overseas education or work (Glick Shiller et al.1995; Waters 2006). Authors also identify that young transnational movers shape the urban landscapes of host destinations through both their bodily presence and the cultural and material modifications brought about by their transnational connections (King and Lulle 2015; Collins 2009). Nonetheless, the relation between transnational connections and temporal mobility has only been theorised to a certain degree. Few authors analyse how transnational youth mobility can be understood as a means of managing precarity and uncertainty. However, Bailey et al. (2002, 125) introduce the concept of 'permanent temporariness' as a strategy for resistance. This concept is very useful when applied to young EEs in Spain, as a 
fundamental feature that characterizes their experiences while practicing mobility for study or for work.

Third, the broader concept of time and temporariness in youth mobility is conceptualised by authors 'as a measurable social construction emphasising the corporeal, sensuous and expressive being of mobile people in relation to experiential time' (Collins and Shubin 2015, 97). Cwerner (2001, 7) establishes the relations between time, culture and migration, and emphasizes different temporal aspects of the migrant experience and their consequences. Griffiths et al. $(2013,4)$ selected aspects of typologies of time that are related with mobility, discussing different inter-related orderings or rhythms of timescales -cyclical, linear, future-orientated, or 'time out'. In turn, Collins and Shubin (2015, 97), following Elder et al. (2004), stress that 'migrant time is a chronological succession of instances' while 'the temporal norms and rhythms of migration are rather non-linear, and often characterised by surprising and divergent experiences'. Following these interpretations, this paper aims to approach mobility both as different moments in time and as part of an unfolding, conceptually linear and nonlinear process.

In order to intensify our understanding of youth experience, and advancing studies in the field of mobility research, this article makes two contributions: first it extends the concept of the life-course in youth studies capturing rhythms as a succession of repetitions and differences that are constantly changing, to emphasize the centrality of the body in temporary mobility. Second, drawing on in-depth interviews, the article (re)activates rhythmanalysis to highlight how diverse rhythms may embrace and contrast the different ways in which the young, in this case EEs who moved to Spain, experience their mobility. To do so, I suggest thinking about the idea that cyclical, 
linear and non-linear processes in youth mobility shape and modulate multiple temporal experiences of mobility across the life-course in ways that translate into experientially distinct rhythms.

\section{Rhythmanalysing temporary mobility}

This article integrates the issue of rhythmic change into the analysis of temporary mobility, taking into account that the invisibility of movements due to open borders, favour the fluid life-course that affects young EEs' mobility experiences. Although there is an increasing body of literature on youth across the life-course, the concern of rhythmic change in mobility remains underdeveloped. In their study, Edensor and Holloway (2008) borrow Lefebvre's concept of rhythmanalysis to consider the tempos and rhythms of journeys, focusing on coach tours in Ireland. There are studies on migration being repetitive (Chapman and Prothero 1983), or on European retirees in Spain (O’Reilly 2000). Recently, Shubin (2015) explored the experiences of EEs during their migration to Scotland, in terms of the complexity of time-space and their openness and co-existence. The specific analysis of rhythmic change experiences of young EEs who practice mobility overseas in times of crisis is, however, scarcely reflected in the literature.

As mentioned above, this paper engages with Lefebvre's rhythmanalysis, developing some of his insights and going beyond his analysis. Two linked concepts are crucial to the analysis of rhythmic change: first, the contrast of 'two very different modalities of 
the repetitive', linear and non-linear, and second, the implied but different notions of polyrhythmia, eurhythmia and arrhythmia (Lefebvre 2004).

First, I focus on the rhythmic change in temporary mobility as an essential concern that recognizes the importance of time in cyclical repetition, differences and discontinuities, but also simultaneity, through a dual perspective that coexists in a dialectical relation and that links different terms together (Lefebvre 1991, 205 quoted in Simpson 2008, 814). On the one hand, I highlight the linear socio-economic perspective, which includes the insertion of migrants into the labour market (in terms of objective entities in the host country), the availability of adequate employment opportunities (related to wages) and working conditions (related to expectations of personal advancement) (Cwerner 2001, 9). From this perspective, time has an objective structure, which means that rhythm could be managed by migrants themselves, and thus associated with considerable freedom but depending, at the same time, on the socio-economic context and developments in the host country (Collins 2012a).

On the other hand, I emphasise the non-linear perspective, the corporeal and sensorial experience of mobility, in which rhythms co-exist with each other beyond human subjectivity. Heidegger's thought is notable for its significance on the harmony of time linked to human subjectivity. Heidegger (1996) considers that human existence is objective and subjective, discontinuous, present, but linked to the past and projected into the future. His ideas allow me to advance a perception of mobile people as subjective, which means that when people lose their temporal continuity, they are not able to control their time, and therefore their rhythm. Thus, time, as a subjective feature of human experience, brings divisions in continuity (for instance the end of a labour contract), affecting both body and mind and causing disruptions and discontinuities. In 
this duality, I insert the meaning of time as a 'social' dimension (Collins and Shubin 2015, 97). Time is understood as a 'complex system comprising multiple articulations of the individual: the objective and the subjective, nature and society, the body and the world, and the spaces of experience, symbol and action' (Mels 2004, 9 quoted in Edensor and Holloway 2008, 483).

Second, I highlight the significance of rhythmic change in temporary mobility, shown in the analysis of arrhythmia, polyrhythmia and eurhythmia in the context of the 'permanent temporariness' (Bailey et al. 2002) present in young lives. This is particularly important for the cases studied here. I analyse how young EEs who practice temporary mobility in Spain try to manage their difficulties, but also their anxiety, despair and pain in facing the precarity of their lives. I focus on the multiple categories of moving, and I argue that the mobile body consists of a bundle of rhythms, different but in tune, and produces a garland of rhythms expressed by metastable equilibrium, composed of difference and repetition, interaction and composition, frequency and measure, but also, disturbances and turbulences.

The different durations of rhythms intersect, and may clash and harmonise, producing reliable moments of regularity or less consistent variance. Inspired by Lefebvre, Edensor and Holloway (2008, 484) suggest that 'these degrees of rhythmic consistency emerge according to the time and space between events, the clustering or separation of elements, their tempo and intensity, the modulations of unpredictability and disruption, and the coinciding effects that produce arrhythmia, polyrhythmia or eurhythmic synchronicity'. If these rhythms are out of synchronization, an 'arrhythmia' is produced; if these rhythms are multiple and interrelated, this produces 'polyrhythmia'; finally, if these rhythms are in harmonious relation, this produces a 'eurhythmia'. 
In mobility, individuals inevitably experience temporal 'tears' or arrhythmic periods especially if the migrant becomes unemployed in the destination country. As Lefebvre pointed out, 'disruptions and crises always have origins in and effects on rhythms: those of institutions, of growth, of the population, of exchanges, of work, therefore those which make or express the complexity of present societies’ (Lefebvre 2004, 44). Hence, economic changes and transformation of techniques of production accompany important movements of population (Elden 2004, 150). Thereby, economic and political control of citizens' everyday lives (Lefebvre 2002) produces disruptions affecting the young lifecourse manifested in the difficulty to leave home, or to secure stable employment trajectories. In the frame of rhythmic change of EE mobility, I depict arrhythmia as several phenomena that occur in a disorderly way, without cadence, variations or repetition, in terms of speeds of time, anxiety, loss, of being 'out of time' (Bailey et al. 2002,138). Mobile young people experience a loss of rhythm caused by their precarious jobs, finalization of contracts, interspersed by periods of unemployment or economic inactivity (Stratford 2014). Studies of educated unemployed youth across the life-course refer to a discourse of arrhythmia, manifested in temporal anxiety (Collins and Shubin 2015; Katz 2004), subjective insecurity, or permanent temporariness, disruptions and uncertainty (Collins 2012a; Bailey et al. 2002).

Nonetheless, the young are not passive in the face of these realities, and temporal discontinuity for study or work are not necessarily negative; they 'hope things will change' (Jeffrey 2010,465). According to Jeffrey (2010, 468) the capacity of the young to regain hope in the face of joblessness rests in part on their inherited social and transnational connections: they possess 'social capital' in Bourdieu's (1986) terms'. 
Through their capacity to overcome difficulties, they experience 'polyrhythmia' -as a process of relative permanence in mobilities that marks the coexistence of two or more rhythms (Collins 2012a, 324). As they move, they leverage their educational qualifications and develop novel cultural and social forms to survive: here and/or there in a temporal permanence. In Bergson's view (1910), permanence is described in relation to duration that is pure heterogeneity; it is not just a subjective feature of human experience, but also an essential characteristic of beings. Following Bergson, I argue that in mobility, duration can be interpreted as experience of freedom to live here or there. In the transnational context, Collins (2012a, 323) raises critical awareness to the interlinked dimensions of permanence and temporality, because the capacity of temporal movers to become part of the labour market in the destination country is often dictated by the disciplining of individual bodies through the rules of regulation of the migration scheme.

Thus, in polyrhythmia, depending on the context, bundles of rhythms intermingle and interact with each other forming complex co-existing rhythmic fields. As Simpson (2008, 816) points out, 'a hybrid polyrhythmia' is produced as a multiplicity of interplayed rhythms functions. In the case of young EEs, there is a vast spectrum of rhythms, making time flow differently depending on whether people attempt to find a job, or wait for the finalization of their temporary employment contract.

Although young people are ‘dwelling in mobility’ (Burrell 2006), some of them have achieved a more stable job that allows them to make their rhythm more flexible and secure, that is, to make it more eurhythmic. I interpret 'eurhythmia' as a constructive, harmonious interaction that produces united -linear/non-linear- rhythms that work 
together. The eurhythmic status is characterised by 'regularity of repetition’ or routine (Ansell et al.2011, 533) in youth temporary mobility, which in this context means a state of stability in their professional careers that consequently brings them harmony in their lives. However, as Ballinger (2012, 399) suggested, 'mobility may break old rhythms and inaugurate new ones as individuals inhabit diverse transnational spaces'. Johnson-Hanks (2002, 878) conceptualizes these situations as 'vital conjunctures' that are moments when seemingly established futures are called on to manage durations of radical uncertainty'. For the young EEs who practice mobility, the analytical concept of vital conjuncture refers to a socially structured zone of possibility that emerges around specific periods of potential transformation in a life: for instance, pursuing a career overseas, or looking for work abroad. It is a temporary configuration of possible change, duration of uncertainty and potential for the future.

Therefore, in this research, EEs who practice intra-European mobility have a different rhythm of mobility that is highly conditioned by their position in the labour market in the country of destination, the duration of their temporary contracts of employment, their acceptance at the foreign university, or the duration of their studies. Having discussed the basic tenets of Lefebvre's rhythmanalysis, as well as providing a provisional rhythmanalysis and highlighting one point of concern, this article shall now provide insights into the discussion of the experiences of rhythmic change of the EE youth who practice mobility in Spain.

\section{Eastern Europeans in the EU and Spain}

The migration from the countries of EE to the EU that followed the fall of the Berlin wall and the EU enlargement has been described as one of the largest and most 
intensive migration flows in contemporary European history (Trevena et al.2013, 671). The evolution of EE migration to the EU and Spain can be divided into three periods. The first period (1990-1996) is characterised by the pioneers of migration. The second period (1997-2002) is characterised by creation of Eastern Europeans' international routes for work that have converged towards the southern region of the EU, while the third period (2002-2015) is characterised by the opening up of the Schengen area borders to Romania and Bulgaria (2002) and their subsequent admission to the EU (2007). During this period, the restrictions to travel involving visa requirements and requisites to prove financial sustainability for the duration of travel were lifted (Careja 2013, 78). This marked a significant growth in the mobility of Romanians and Bulgarians. The two main destination countries have been Italy and Spain which together housed more than $70 \%$ of all Bulgarian and Romanian nationals resident in another Member State (European Commission 2011). Despite the consequences of the economic crisis, which have been widely attributed to the adverse developments in the construction sector, the mobility of Romanians and Bulgarians to Spain has continued to increase.

Mobility thus became a central issue in the enlarged EU favoured by the right of EE citizens to move freely (Recchi and Favell 2009). In 2015, there were an estimated 967,334 Romanians and 185,251 Bulgarians living in Spain ${ }^{1}$. In this context, the mobility of young EEs is a phenomenon that has gained importance (Marcu 2015a, 70). As the Report from the European Commission (2011) noted, mobile EE workers are younger than the overall population in both sending and receiving countries. The under 35 s represent $62 \%$ of the Romanian and Bulgarian economically active working-age movers compared to only 34\% in the EU-15 labour force (European Commission 2011). 
Several studies (Glystos 2009; Baláz et al. 2004) have shown that young people are particularly inclined to leave their countries for temporary education and employment abroad. Marcu (2015a,70) pointed out that 'young people from Eastern Europe have different motives, role models and relational dynamics shaping their spatial choices, including the desire to study at a well-recognised university, free movement for employment purposes within the EU, the impact of training on future career prospects, job opportunities, or relational ties created by transnational migrant communities’.

\section{Methodology}

The aim of this paper -to explore experiences of mobility in terms of rhythmic changesuggests the use of qualitative research. Rhythmanalysis, as a key method and a useful tool that reproduces connections between individuals and the social, provides the basis on which qualitative rigour is being evidenced leading to new understandings.

I conducted 60 in-depth semi-structured interviews with young EEs (Romanians and Bulgarians) in Spain and in the waiting rooms of the international airports of Bucharest and Sofia: 30 Romanians -17 females and 13 males- and 30 Bulgarians -19 females and 11 males-. The interviews were held between November 2012 and July 2013. In Spain, 40 people were interviewed, 20 Romanians and 20 Bulgarians: Madrid (14) Barcelona (13) and Valencia (13). In the airports of Bucharest and Sofia, 20 people were interviewed, 10 in each. Although at the time of the interview respondents lived or travelled to/from Spain, the sample also contained people who lived in Spain continuously, only a few months a year. It is important to note that this is a feature of current youth mobility in the context of the enlarged EU. The men and women who were interviewed were Romanian and Bulgarian young (between 19 and 33 years old) 
who had moved from their country in the last two or three years and who had spent at least one year in the same city (Marcu 2015a, 71). Some of them came to participate in the project through Student Associations of Eastern Europe in Spain, while others came through personal contacts and the subsequent snowball sampling. First, respondents were asked about their situation before moving, and how many times a year they travel between their country of origin and destination, or other countries, including the reasons why and the time spent in either country. Second, we discussed their mobility experiences in terms of rhythm of study and job opportunities in the destination country, and the extent to which these experiences had shaped their perceptions of the country. I asked if they work or study, and if their life had changed after finishing their studies in terms of movement. I enquired as to whether they travel more often or less often to their country of origin, or to other countries, after completing their studies. Third, they were asked about their perceptions and feelings about rhythm, that is: if the rhythm is part of their life while moving, and if they consider and feel the rhythm while moving. All these questions aimed to capture the rhythm of young EEs while practicing mobility. I conducted the interviews in Romanian and Spanish and translated and transcribed them before undertaking the analysis. In this study, all participants appear under pseudonyms to ensure their anonymity.

The interviews were coded and analysed using the ATLAS ti qualitative analysis software. The issues that emerged from the interviews were analysed as follows: the arrhythmic mobility reflected by disturbances and rupture, the polyrhythmic mobility situated between instability and flexibility, and finally, the eurhythmic mobility composed of diverse and equilibrate rhythms. As Frändberg argues (2015, 558) 
'narrative analysis directs attention towards the relationship between events and how people understand and organise their experience'.

\section{Rhythmic change in temporary mobility: experiences of young Eastern Europeans}

This section contains the main empirical findings of the research. I interpret Lefebvre's rhythmanalysis as a means to make sense of the various characteristics of rhythm and how these are related in young people's experiences in order to explore the rhythmic change in temporary mobility. In outlining the 'previsionary portrait' of the rhythmanalyst, Lefebvre (2004, 33) notes that a rhythmanalyst may build a dialectical relation between the present and presence. As he stresses, the act of the rhythmanalysis transforms everything into presences including the present, grasped and perceived as such. This leads to the concern of presencing that in Heidegger's thought is not dependent on humans. Heidegger (1996) goes beyond human subjectivity, highlighting inter-subjectivity in time-space; the encounter between people and things in the world. As Shubin (2015, 352) argues, 'this attention to the process of presencing (timing and spacing rather than static 'presentness') highlights the importance of attunement and instantaneity'. I adopt this approach to show how the migrants feel while moving; how they can experience and overcome their loss and unpredictability in a changing world.

Lost again: 'arrhythmic’ mobility 
In Lefebvre's thought $(2004,16)$, rhythms unite with one another in the state of health in normal everydayness. When they are discordant, a pathological state arises, in which arrhythmia is generally at the same time, symptom, cause and effect. I extend these assumptions to the context of temporary mobility, emphasising that in this research, the lack of rhythm is closely related to the loss of employment, which is both caused by and further enhances precarity and uncertainty.

I emphasise that a fundamental factor that determines the choice and thus, the change of place in youth temporary mobility, is highly conditioned by the context of crisis and economic changes, which affect the choice of the young when looking for employment strategies in other countries.

In my Spanish fieldwork I observed the difficulty of unemployed young people who practice temporary mobility to establish a rhythm in their everyday life. Of the 60 respondents, 22 reported to have worked temporarily, but at the time of the interview were unemployed. Of these 22, 18 had completed their studies and were seeking employment, while 4 were still studying.

I found that when respondents lost their jobs, they also lost the possibility of practicing mobility as before. According to the official data, the youth unemployment rate of Romanians in Spain in 2015 was $61.8 \%$ while for Bulgarians it was $59.4 \%{ }^{2}$ The end of an employment contract and the slow process of finding a new job produce disturbance, precarity, and rhythmic change in mobility.

Ivan recognized:

I have just finished a contract in a Spanish department store. I can't think what I'll do, or where I'll go. I cannot travel as before, I'm out of time...The only rhythm I have is 
every morning I pull out of my suitcase, which is packed and ready for leaving, the clothes I'm going to wear that day. (Male, Bulgarian, age 26)

Ivan's discourse is helpless against the reality of his life. For him as for most of the respondents, work becomes the centre of his life, it is the essence of time. In losing his employment contract, he lost his time and thus, lost his rhythm. On the one hand, the loss of work triggers events that occur in a disorderly way, without measure or repetition. On the other, young people's employment insecurity leads to subjective insecurities being evidenced in the loss of rhythm in the psychic state of the individual: career, residence and professional identity, but also their physical and emotional health, are all at stake.

At this point arrhythmia sets in, which in the context of the Spanish economic crisis and the lack of employment makes it difficult to maintain an adequate rhythm of mobility. Thus, mobility for work produces a temporal disruption of rhythm if the migrant is unemployed and reflects, 'the concatenation of multiple spatio-temporal insecurities: the disappointment of being unable to acquire secure salaried work despite having spent a long time in formal education, the frustration of being unable to travel and the sense of loss that accompanies being removed from spaces associated with modernity and development' (Jeffrey 2010, 477). Bourdieu $(1984,150)$ referred long ago to the 'broken trajectory effect', wherein young people fail to obtain the occupation they were led to expect.

Some respondents said they wanted to get back the rhythm lost, (re) integrate into Spanish society, even look for work in other countries, or return to their countries, but they expressed their insecurity as to how they might achieve these objectives. 
Simona reflected:

It is difficult to know what I will do, and when I will have enough money to return to my country. Some days I think about looking for a job here, other days about going to England or a Nordic country, and days when I don't want anything. I don't even feel like going out. Also, time flies by, you don't know where it goes, but my time is inordinately slow. (Female, Romanian, age 27)

The comparison between speeds of time perceived as incessant, the plurality of options that remain in the background and the slowness of the present that evades control constitute Simona's arrhythmic experience of mobility. As Sheller (2011,2) noted 'temporalities speeds or slowness are parts of wider sensorial geography of body in mobility'. Thus, corporeal and sensorial experience is also captured in an arrhythmic way; the loss of rhythm being accompanied by anxiety and feelings of insecurity. Collins and Shubin $(2015,101)$ argued that 'anxiety is an attunement that manifests the loss of stability in life, often linked to a disruption of accustomed routines and temporal rhythms by an event, encounter or experience'. Given their precarious circumstances, respondents develop anxiety disorders, experiencing feelings of sadness, emotional distress, guilt or despair.

Mihai confessed that:

I'm desperate...I'm so exhausted... What can I do? How can I get out of this situation? While studying, I knew that in summer I could go home. Now, I can't because I can't afford to. I have no job, no prospects of any kind. At the moment, I have no plan, no rhythm. (Male, Romanian, age 24) 
Mihai's narrative reveals physical tiredness and emotional anxiety; joblessness has led to a lack of rhythm and the despair he feels as a result of being unable to practice mobility. Thus, 'non-linearity in individual life-courses can be understood through the experiences of discontinuities that are reflected in the body by feeling of instability, irritability, and dizziness, which are characteristic of anxiety’ (Hörschelmann 2011, 378).

However, anxiety and getting out of rhythm potentially may pose a new way of life that can ensure a continuous living out of new experiences. Respondents manifested that the frictions between rhythms are not entirely negative, as they open new and surprising possibilities for action. Anxiety, thus, opens up opportunities and generates a desire for different sorts of being in the world, even as those modes of being remain unknown (Collins and Shubin 2015,102).

Todor said:

With each change of place, I lose my rhythm. I get to a place and I have nothing, but there is hope that tomorrow could be another day... (Male, Bulgarian, age 22)

Todor's confession brings to the forefront hope as a potential symbol to rediscover the rhythm and confidence that will bring him the opportunity to change his life. The capacity to aspire and the potential to transform thought into experiences become a source of hope, even if plans often remain just that, an imagined project. Hope is thus, the passive counterpart of desire, the field of desire in waiting (Crapanzano 2004). As my interviewee said, 'hope is the last thing to go'. The ability to imagine a more comfortable future is in itself part of the crafting of meaningful and purposeful lives. 
Thus, a rhythmic change is produced, and hybrid polyrhythmia emerge as a multiplicity of interrelated rhythms functioning independently of one another, but influencing each other (Simpson 2008).

Living between rhythms: 'polyrhythmic' ways to experience mobility

From his Parisian window, Lefebvre perceives the body in a spatial simultaneity that interact polyrhythmically. In this research, rather than being perceived, polyrhythmia is experienced as a rhythmic change process that marks mobility in several 'ways in which different aspects of space, time and life-course intersect in relation to the multiplicity of demands that are experienced on a daily basis' (Jarvis et al.2011,519). While moving, the young perform in space-time, becoming immersed in everyday life activities fused with spatial and natural rhythmical events. They experience different rhythms of mobility, as they live somewhere between precarity and flexibility. This variety of rhythms creates the polyrhythmic mobility practiced by young people looking to study or work and expressed by uncertainty on the one hand and the possibility of establishing a professional rhythm in their lives on the other.

Some 20 respondents interviewed in this category change country of destination with a certain rhythm. Given the short temporary contracts, they are forced to travel constantly. According to official data, the temporary employment rate of young Romanians and Bulgarians in Spain in 2015 was 68\%, and 67.6\%, similar to that of young Spaniards $(67.2)^{3}$. During the summers, respondents usually work in tourism in Spain, while during the academic year they study in British universities. As Gardiner $(2000,6)$ noted, 
mobility 'can be polydimensional: fluid, ambivalent and labile', and is 'constantly attaching, weaving and disconnecting; constantly mutating and creating' (Harrison 2000,502).

This is noted by Miroslava:

During the summers, I travel from the UK, where I study, to Spain and seek work at a café on the coast. For Christmas, I always like to go to Bulgaria. But I never know in advance if I can keep these rhythms up, because there may be differences, it all depends on the circumstance of my life. (Female, Bulgarian, age 21)

Miroslava's (poly)rhythmic change, focuses on 'cyclical repetition and the linear repetitive that interfere with one another constantly' (Lefebvre 2004,8). Thus there is no identical absolute repetition indefinitely. As Deleuze $(1994,27)$ notes 'the meeting between difference and repetition come about as a result of interferences and intersections between the essence of repetition and the idea of difference'. Furthermore, Johnson-Hank $(2002,871)$ suggests that although most social life may be thought of as conjectural, in the sense that action is conjoined to a particular temporary manifestation of social structure, vital conjunctures interfere as critical durations when more than usual is in play, when the futures at stake are significant.

Some respondents said they find it difficult to establish a rhythm in their temporary mobility as each year they have to adapt to the reality of the society in which they live. They are involved in high job insecurity and the need to engage in a number of different jobs at any one particular time (Cwerner 2001, 9). Living in precarious conditions in the context of the Spanish labour market, in relative permanence they recognize that if it is necessary to change country to have the opportunity to find a job, they are willing to do 
so. This causes insecurity and distress while trying to draw a balance between their reality and their desire for change.

Mihnea remembered:

Last year I spent a few months in Norway, three weeks in London...some months in Spain...I change destination country depending on whether I find work or not. I never know where I'll go. When I don't have work, I cannot travel. I feel empty and have the feeling of an irremediable loss of rhythm. However, I have so much to do... Whatever happens... I have a lot of projects... and I will seek the adequate rhythm. (Male, Romanian, 27 years)

Mihnea experiences the multiplicities of rhythms that change depending on the rhythm of his work in several Europeans countries. It is interesting to note the life-course mobility strategy that Mihnea works out to successfully cope with the uncertainty of the context. He is determined to find a rhythm, whatever happens, whatever unexpected events emerge on the horizon to recoup a planning dimension, and control the rhythm of his mobility projects (Liversage 2009). This attitude is quite distinct from the first 'arrhythmic' group, because the principles of polyrhythmic actions appear that serve as a general tool of orientation and hence as an antidote to uncertainty. Accordingly, a polyrhythmic change may be an 'antagonistic unity of relations' that sometimes 'rises to compromises, sometimes to disturbances’ (Lefebvre 2004, 8).

When asked if they feel the rhythm, how they keep rhythms with their temporary mobility and how they experience it, respondents highlighted that mobility between 
various locations, and temporal intensity with that practice, makes them feel distinct rhythms.

Viorela told me:

I live and feel the rhythm differently when I make a trip to find work, to sign a contract, or to start a new job. I have lived all these experiences, they are fast, intense rhythms. When I return to my country on vacation, the rhythm is slower, calmer... When I am with my family I live it with nostalgia, wanting to rest soundly on a beach. It is when I disconnect from everything and I feel calm, peaceful. (Female, Romania, age 25)

In contrast with Simona's perceptions from the arrhythmic group, who felt that the slowness of her time was out with her control, Viorela describes her feelings as rhythmical, and according to the principles of multiplicity of polyrhythmia, distinguishes between fast rhythms of mobility, portrayed as complex, busy and agitated, and everyday social life, described as repetitive, accelerated and homogenized. In contrast, the slow rhythm of the holidays might be conceived as quiet and fluid. The interviews, thus, highlight the existence of a multiplicity of rhythms that the respondents experience while moving. As Edensor and Holloway $(2008,485)$ rightly noted, this multiplicity of rhythms is articulated in Lefebvre's insistence on the indissolubility of time and space, which need to be thought together rather than separately. Indeed, this indissolubility, in some cases, leads to rhythmic change towards harmony in mobility.

Towards 'eurhythmic' movement? 
Eurhythmia, according to Lefebvre $(2004,68)$, involves the union of 'rhythms [...] in normal everydayness' and has one objective: to strengthen or re-establish eurhythmia. In the context of EE youth mobility, the eurhythmic state means establishing some sort of stability in the temporary mobility rhythms. Among the 18 interviewees who practice mobility between Spain and other countries with a certain harmonic rhythm of mobility, I found several situations that classify them into three categories.

First, I distinguish the mobility experience of students pursuing a degree abroad, in this case Spain, and who maintain the same rhythm of return to their country of origin. Lindh (1998, 63-64) suggests that when the same kind of trip is made a number of times, the decision process is routinized. The rhythm turns into a habit or action that is always repeated invariably, and that as Lefebvre stresses 'is mechanical in humans' (Lefebvre 2004, 39). However, feelings may interfere in this routine. In this point, I emphasise that the concept of rhythm ('ritm' in Romanian; 'ritmo' in Spanish, and 'Ритъм' (ritŭm) in Bulgarian ${ }^{4}$ ) linked to routine, may have special language connotations, especially in Bulgarian.

Asen explained:

I study in the UK, and I usually go back to my country twice a year to meet up with my family; in summer and for Christmas, when, each year we watch together on television the Vienna New Year's Concert ... Seeing them again, listening to the music with them, means peace of mind for me, and so I am able to keep up my usual [Pumbм (ritŭm)], rhythm. (Male, Bulgaria, age 21) 
The eurhythmic status of Assen is reminiscent of a ritual, since the same routine of homecoming seems to offer the quiet of melodic rhythm to his rest time. This may suggest that in his Christmas return there is some ritual ceremony bound to a wider space of his belonging. Moreover, this rhythmic ordering fosters a sense of being in place, whereby regular routines constitute regular patterns of social practices, and experiences that globalize notions of dwelling (Edensor and Holloway 2008, 487).

Second, I found the respondents who maintain or change their rhythm of mobility depending on their employment contract period or study grants. The availability of financial resources contributes to the eurhythmic movements between the country of origin and Spain, which are regular and orderly throughout the year. However, there is always the possibility of the rhythm being broken or disrupted when the contract or the grant ends.

As Claudia claimed:

I have a five-year contract. I have had the same rhythm of movement for the last three years. This is how my company works and I have adapted to their rhythms. Another thing is what will happen when the contract ends, because my employment contract has an end date... I'm afraid to think about it ... (Female, Romania, age 28)

Claudia's comments reveal that respondents live their current rhythms, but at the same time are aware that potentially these may be lost through, for example, the end of a contract. This may cause feelings of fear and anxiety showing that the limit between eurhythmia and arrhythmia is sometimes fragile. As Edensor and Holloway (2008, 485) 
stress 'any suggestion of a fixed, harmonic temporal scenario is dispelled since rhythms continually change, intersecting and flowing in diverse ways, and apparently repetitive and regular rhythmic patterns are apt to be punctured, disrupted or curtailed by periods of arrhythmia'. Time is 'paradoxical; it folds and twists [...] - here interrupted, there vertical, mobile, and unexpected' (Serres and Latour 1995, 58). Therefore, the harmony of rhythm in motion is rather a temporary state in the overall context of current temporary mobility.

Finally, I found a third category of exceptionally few cases among the interviewees: respondents who had a job in Spain corresponding to their level of training, and who practice mobility between their country and the host country regularly when they go on holiday, or when practicing tourism. However, as Lefebvre $(2004,6)$ noted, 'there is no identical absolute repetition [...] there is always something new and unforeseen that introduces itself into the repetitive'.

Rossen said:

I work at the University with a permanent contract, I am so lucky in that sense... and I move to my home country once a year, in summer. I keep this rhythm, although sometimes a stay abroad arises and I have to go for a month or more, but it depends on the year. (Male, Bulgaria, age 33)

Hence, the circumstances may change and these slight switches provide innovation and harmony to the rhythm. For my respondents, having a permanent contract is a very positive thing that they evaluate as 'lucky'. The harmony, thus, is reflected in the security of having a job offer, which in turn ensures them harmonious rhythm not only 
in mobility but in work and rest. As Still (1985, 39-42) noted 'we must learn to act properly with a due balance of rest and work, which we may say is to work from a position and attitude of rest'.

This is that Ivana explained:

I like to organize my movements, feel and enjoy the rhythm while working, travelling, or resting. I found that maintaining a rhythm gives me positivity and stability in my life, and helps me to plan my future. (Female, Bulgaria, age 32)

Being in continuous employment allows respondents to organize their temporary movements. They want to look ahead, anticipate, and plan their future. Thus, in temporary mobility eurhythmia may be understood as an aspect of movement and a becoming in which cyclical rhythms are wrapped 'in harmonious rhythms of mental and social function' (Lefebvre 2004, 8). Nevertheless, as Edensor (2010b,15) reminds us, 'this status can never be wholly, triumphant, in a set of rhythms that are constantly changing' and that, sometimes achieving eurhythmia, where stability persists, sometimes producing polyrhythmic multiplicity of rhythm, and sometimes reaching arrhythmia, where they 'jar and clash'. This reveals that, in temporary mobility, individuals are immersed in a perpetual wheel rhythmic change.

\section{Conclusions}

By drawing on Lefebvre’s approach of rhythmanalysis, this paper makes a theoretical and empirical contribution, highlighting how the analysis of rhythms might be applied to exploring the temporary mobility experiences of young EEs in Spain after the EU 
enlargement. I further develop Lefebvre’s ideas and present new conceptual additions to advance in the geographical understanding of rhythm in relation to mobility during the life-course.

Lefebvre's approach to rhythmanalysis aimed not only to find a new mode of analysis but to make progress and enhance the conceptual development. He suggests focusing on experiences of rhythms, not just observing them from a distance. Expanding his theorization, this paper first suggests an innovative approach that is not limited to mere observation, but rather uses rhythmanalysis as a qualitative method drawing on in-depth interviews and involving the respondents themselves in the analysis, as participants that experience rhythmic change. If an outside observer can distinguish, classify and analyse the rhythms detected in the fieldwork, a participant, through the interview process, can experience the variations, repetitions or disruptions of rhythms, feel them, interpreting his own choreography of rhythmic change.

The issue of rhythmic change as a conceptual contribution incorporates another lived dimension of rhythmanalysis that enables us to re-think arrhythmia, polyrhythmia and eurhythmia, as essential keys to exploring temporary mobility experiences during the life-course. The analysis of these elements together confirm the argument that the EU socio-economic context, alongside the different professional status of the young people engaged in temporary mobility create multidimensional rhythms that can be broken, mixed or harmonious. Rhythmic change thus shapes young people's experiences presenting both constraints and opportunities in temporary mobility. This leads to the connection between rhythmic change and transnational mobility and its subjectivity which 'may transform the life-course' (Ansell et al. 2011, 537). On the one hand, 
subjectivity may question the linear character of life-course, introducing the need to accommodate uncertainty by which rhythms can be broken and mixed. On the other hand, subjectivity may question life-course, as some of these rhythms relate to social, economic or political events beyond the individual.

While Lefebvre pays attention to how bodies register interplay of cyclical and linear rhythms, as each living body constitutes an interaction of biological and social dimensions this research unravels Lefebvre's thought on rhythms, bringing a more nuanced attention to the non-linear perspective, and analysing not only the importance of body 'that serves as a metronome' (Lefebvre 2004,19) but also the importance of human subjectivity as being-in-the-world, moving, perceiving, acting, thinking, and feeling (Prior 2011,206). Thus, the perspective of rhythmic change in the context of precarious temporariness allows us to explore emotional and spiritual connections manifested in terms of anxieties, uncertainties or hope, on the scale of body and mind, as ‘divergent experiences’ in temporary mobility (Collins and Shubin 2015,97).

Second, the findings that have been identified in this research, which are rhythmic change expressed in 'arrhythmic' mobility, reflected by disruptions and loss, the 'polyrhythmic' mobility, situated between unpredictability and flexibility, and the 'eurhythmic' mobility, composed of diverse and equilibrates rhythms, may have wider applications in other mobility context. Lefebvre's thought offers to the geographers engaged in mobilities a framework to analyse the interplays of rhythms, taking into account the fluid life-course which affects the mobility experience (Findlay et al. 2015). Further research could explore the rhythmanalysis both quantitatively and qualitatively, as a sophisticated analytical tool, for highlighting, for example, different transitions and 
disruptions in life: from work to retirement, from marriage to the dissolution of marriage, or from having a family with children to being an empty nester. Disruptions may also be applied to the analysis of children's experiences of separation from their parents during the processes of intra-European family migration, or in the broken rhythm of refugees -from children to the elderly- who abandon their homes, seeking a new life in Europe. Likewise, rhythmic change may be used to raise mobility in lifestyle migrants who move abroad in order to find rest and thus harmony in their life, or in highly-skilled migrants who are being recruited by transnational companies, experiencing (poly)rhythmic change in their mobility.

Third, I underline the significance of this paper at a time when society (media and policymakers, specifically), might argue that the most important questions in research on human mobility are nowadays issues such as the plight of migrants who lose their life in the Mediterranean Sea, or the disciplining of mobile young radicalized people fleeing to Syria to fight for the so-called Islamic State (ISIS). Without minimizing these pressing concerns affecting global mobility and requiring deep analysis, I highlight the issue of rhythmic change in experiencing temporary mobility as an increasingly significant phenomenon. The socio-economic adversities suffered by EEs in the last 25 years, but mainly, the latter European recession that amplified the rate of unemployed youth affecting the EU $(23 \%)^{5}$ and especially Spain $(51.7 \%)^{6}$ force young people to practice mobility in search for more dynamic and advantageous professional environments, expanding intra-European mobility. Analysing rhythmic change in temporary mobility may help to understand how youth experiences of movement manifested by loss, uncertainty, flexibility or opportunity, are consequences of the high temporality and employer demand, the labour market flexibility, the increasingly 
polarized professional trajectories for the young nowadays, or the expansion of higher education. All of these factors potentially may become a priority for European policymakers to develop measures aimed at promoting the creation of employment (O’Reilly et al. 2015) and thus improving the youth experiences of mobility.

To conclude, this research also suggests the way in which young EEs who are on the move in the EU are able to shape a 'particular culture of time' (Cwerner 2001, 17) around the issue of rhythm, through their participative experiences and feelings. Despite their permanent and precarious temporariness (Bailey et al. 2002), they have the sharpness to edify a dynamic life-course that is based on rhythmic change in their transnational mobility. In this fashion, a Lefebvrian rhythmanalysis approach helps develop as Edensor stresses, a fuller, richer analysis of these synchronic rhythmic experiences in time-spaces while also accounting for qualities, sensations and intersubjective habits (Edensor 2010b, 2). This fact might make us think, as Shubin (2015) recently noted, about the complexity of time-spaces in terms of their openness and co-existence, considering movers' lives as open-ended and incorporating a multiplicity of futures, presents and pasts.

\section{Notes}

\footnotetext{
${ }^{1}$ Ministry of Employment and Social Security, Spain

http://www.empleo.gob.es/es/estadisticas/Inmigracion_emigracion/index.htm (accessed 28.12.15).

${ }^{2}$ Ministry of Employment and Social Security, Spain

http://www.empleo.gob.es/es/estadisticas/Inmigracion_emigracion/index.htm (accessed 23.12.15).

${ }^{3}$ Ministry of Employment and Social Security, Spain
} 
http://www.empleo.gob.es/es/estadisticas/Inmigracion_emigracion/index.htm (accessed 14.12.15).

4 Although the Bulgarians' interviews were conducted in Spanish, respondents may interpret the meaning of rhythm as in their native language. In the literal sense of the word, rhythm is translated as ritual, and so becomes synonymous with this meaning.

${ }^{5}$ Eurostat http://ec.europa.eu/eurostat/statisticsexplained/index.php/Unemployment_statistics (accessed 28.11.2015).

${ }^{6}$ Eurostat http://ec.europa.eu/eurostat/statistics-

explained/index.php/Unemployment_statistics (accessed 29.11.2015).

\section{References}

Ansell N, van Blerk, L Hajdu F and Robson E 2011 Spaces, times, and critical moments: A relational time - space analysis of the impacts of AIDS on rural youth in Malawi and Lesotho Environment and Planning D 43 524-544

Bailey AJ 2009 Population geography: life-course matters Progress in Human Geography 33 407-418

Bailey AJ, Wright RA, Mountz A and Miyares IM 2002 (Re)producing Salvadoran transnational geographies Annals of the Association of American Geographers 91 125144

Baláz V, Williams A and Kollár D 2004 Temporary versus permanent youth brain drain: economic implications International Migration 42 3-34

Ballinger P 2012 Borders and the rhythms of displacement, emplacement and mobility in Wilson TM and Donnan H eds A Companion to Border Studies Wilson/A Companion to Border Studies John Wiley \& Sons Chichester, New York 387-404 
Bergson H 1910 Time and Free Will Swan Sonnenschein, London

Bissell D 2009 Visualising everyday geographies: practices of vision through traveltime Transactions of the Institute of British Geographers 34 42-60

Bourdieu P 1986 The forms of capital in Richardson J G ed Handbook of Theory and Research in the Sociology of Education Greenwood Press, New York 241-258

Bourdieu P 1984 Distinction: A social critique of the judgment of taste Routledge and Kegan Paul, London

Burrell K 2006 Moving lives: narratives of nation and migration among Europeans in post-war Britain Ashgate, Aldershot

Careja R 2013 Emigration for development? An exploration of the State's role in the development-migration nexus: the case of Romania International Migration 51 76-90

Chapman M and Protero R M 1983 Themes on circulation in the third world International Migration Review 17 597-632

Collins FL and Shubin S 2015 Migrant times beyond the life-course: the temporalities of foreign English teachers in South Korea Geoforum 62 96-104

Collins FL 2012a Transnational mobilities and urban spatialities: notes from the AsiaPacific Progress in Human Geography 36 316-336

Collins FL 2012b Researching mobility and emplacement: Examining transience and transnationality in international student lives Area 44 296-304 
Collins FL 2009 Connecting 'home' and 'here': personal homepages in everyday transnational lives Journal of Ethnic and Migration Studies 35 839-860

Crapanzano V 2004 Imaginative horizons. An essay in literary philosophical anthropology University of Chicago Press, Chicago

Cresswell T 2010 Towards a politics of mobility Environment and Planning D: Society and Space 28 17-31

Cwerner S 2001 The times of migration Journal of Ethnic and Migration Studies 27 736

Deleuze G 1994 Difference and repetition University Press, New York

Edensor T 2010a Walking in rhythms: Place, regulation, style and the flow of experience Visual Studies 25 69-79

Edensor T 2010b Introduction: Thinking about rhythm and space in Edensor $\mathbf{T}$ ed Geographies of rhythm: Nature, place, mobilities and bodies Ashgate, Farnham 1-18

Edensor T and Holloway $\mathbf{J} 2008$ Rhythmanalysing the coach tour: the Ring of Kerry, Ireland Transactions of the Institute of British Geographers 33 483-501

Elden S 2004 Understanding Henry Lefebvre Continuum, London

Elder G, Johnson M and Crosnoe R 2004 The emergence and development of life course theory in Mortimer J Shanahan M eds Handbook of the Life Course Springer, New York 
European Commission 2011 Report from the Commission to the Council on the Functioning of the Transitional Arrangements on Free Movement of Workers from Bulgaria and Romania (SEC 1343 final) Brussels, 11 Nov COM(2011) 729 final

Findlay A, McCollum D, Coulter R and Gayle V 2015 New mobilities across the life course: a framework for analysing demographically linked drivers of migration Population, Space and Place 21 390-402

Findlay A, King R, Smith F, Geddes a and Skeldon R 2012 World class? An investigation of globalisation, difference and international student mobility Transactions of the Institute of British Geographers 37 118-131

Frändberg L 2015 Acceleration or avoidance? The role of temporary moves abroad in the transition to adulthood Population Space and Place 21 553-567

Gardiner M 2000 Critiques of everyday life Routledge, London

Glick Schiller N, Basch L and Szanton Blanc C 1995 From immigrant to transmigrant: theorizing transnational migration Anthropological Quarterly 68 48-63

Glystos N 2009 Theoretical considerations and empirical evidence on brain drain: grounding the review of Albania’s and Bulgaria’s experience’ International Migration 48 108-130

Griffiths M, Rogers A and Anderson B 2013 Migration, time and temporalities: review and prospect Compass Oxford 
Hannam K, Sheller M and Urry J 2006 Editorial: Mobilities, immobilities and moorings Mobilities 11-22

Harrison P 2000 Making sense: embodiment and the sensibilities of the everyday Environment and Planning D: Society and Space 18 497-517

Heidegger M 1996 Being and time SUNY Press, Albany NY

Hörschelmann K 2011 Theorising life transitions: geographical perspectives Area 434 378-383

Jarvis H, Pain R and Pooley C 2011 Guest editorial: Multiple scales of time-space and life-course Environment and Planning A 43 519-524

Jeffrey C 2010 Timepass: Youth, class, and time among unemployed young men in India American Ethnologist 37 465-481

Johnson-Hanks J 2002 On the limits of life stages in Ethnography: Toward a theory of vital conjunctures American Anthropologist 104 865-880

Katz C 2004 Growing up global: Economic restructuring and children's everyday lives University of Minnesota Press, Minneapolis

King R and Lulle A 2015 Rhythmic Island: Latvian migrants in Guernsey and their enfolded patterns of space-time mobility Population, Space and Place 21 599-611

Lefebvre H 2004 Rhythmanalysis: Space, time and everyday life Continuum, London 
Lefebvre H 2002 Critique of everyday life Volume II. Foundations for a Sociology of the Everyday Verso, London

Lefebvre H 1996 Writings on Cities Blackwell, Oxford

Lefebvre H 1991 The Production of Space London, Blackwell

Lindh C 1998 Decision processes in discretionary long-range travel Department of Infrastructure and Planning Royal Institute of Technology, Stockholm

Liversage A 2009 Vital conjunctures, shifting horizons: high-skilled female immigrants looking for work Work Employment \& Society 23 120-141

Marcu S 2015a Uneven experiences of mobility. Life-strategy expectations among Eastern European undergraduate students in the UK and Spain Geoforum 58 68-75

Marcu S 2015b From the marginal immigrant to the mobile citizen: Reconstruction of identity of Romanian migrants in Spain Population Space Place 21 506-517

May J and Thrift N 2001 Timespace: Geography of temporality Routledge, London

Mels T 2004 Reanimating places: A Geography of rhythms Ashgate, Aldershot

Murphy-Lejeune E 2002 Student mobility and narrative in Europe: The new strangers Routledge, London 
O`Reilly J, Eichhorst W, Gábos A, Hadjivassiliou K, Lain D, Leschke J, McGuinness S, Kurekova L M, Nazzio T, Ortlieb R, Russell H and Villa P 2015 Five characteristics of youth unemployment in Europe: flexibility, education, migration, family legacies and EU policy Sage Open January-March 1-19

O'Reilly K 2000 The British on the Costa Del Sol. Transnational identities and local communities Routledge, London

Prior N 2011 Speed, rhythm, and time-space: museums and cities Space and Culture 14 $197-213$

Recchi E and Favell A 2009 Pioneers of European integration. Citizenship and mobility in the EU Edward Elgar, Cheltenham

Serres M and Latour B 1995 Conversations on science, culture, and time Ann Arbor, The University of Michigan Press

Sheller M 2011 Mobility Sociopedia.isa DOI: 10.1177/205684601163

Shubin S 2015 Migration timespaces: a Heideggerian approach to understanding the mobile being of Eastern Europeans in Scotland Transactions of the Institute of British Geographers 40 350-361 
Simpson P 2008 Chronic everyday life: rhythmanaysing street performance Social and Cultural Geography 9 807-829

Still W 1985 Rhythms of rest and work Gilcomstone South Church, Aberdeen

Stratford E 2014 Geographies, mobilities and rhythms over the life-course: adventure in the interval Routledge, New York

Trevena P, McGhee D and Heath S 2013 Location, Location? A critical examination of patterns and determinants of internal mobility among post-accession Polish migrants in the UK Population Space and Place 19 671-687

Urry J 2007 Mobilities London, Polity

Waters J 2006 Geographies of cultural capital: education, international migration and family strategies between Hong Kong and Canada Transactions of the Institute of British Geographers 31 179-192 